\title{
Tumor Formation and $\beta$-Glucuronidase Expression in Phaseolus vulgaris Inoculated with Agrobacterium tumefaciens
}

\author{
Mark E. Lewis ${ }^{1}$ \\ Department of Horticulture, University of Wisconsin, Madison, WI 53706 \\ Fred A. Bliss ${ }^{2}$ \\ Department of Pomology, University of California, Davis, CA 95616 \\ Additional index words. common bean, transformation, pKIWI105, tumorigenesis, GUS, acetosyringone
}

\begin{abstract}
Ten common bean (Phaseolus vulgaris L.) lines-including cultivars, breeding lines, and one wild line-were evaluated for susceptibility to Agrobacterium tumefaciens strain C58 by stab-inoculating intact shoot tips of germinating seeds. Significant differences for tumor frequency and size were found on the resulting 3-week-old seedlings. UW 325, a wild bean, had the highest rate of tumorigenesis; 'Olathe', a dry bean cultivar, had the lowest. Uninoculated excised shoot tips cultured in media with BA or BA plus NAA exhibited differences in phytohormone sensitivity, as evidenced by callusing and root initiation. The cultivar Montcalm seemed to be highly sensitive, while 'Olathe' was relatively insensitive. Fluorometric GUS assays of shoot tips from germinating seeds inoculated with the disarmed GUS-containing $A$. tumefaciens strain C58C1(pGV3850/pKIWI105) showed that UW 325 had the highest level of GUS activity. 'Montcalm' had a high rate of tumorigenesis but a low level of GUS activity; this anomaly was attributed to its high phytohormone sensitivity. The use of the virulence-inducing compound acetosyringone in the inoculum culture medium did not alter genotypic differences (ranks) in susceptibility. Histochemical GUS assays of inoculated UW 325 shoot tips showed that $60 \%$ of the apexes exhibited one or more transformation events. Chemical names used: $\beta$-glucuronidase (GUS); $\alpha$-naphthaleneacetic acid (NAA); $N$-(phenylmethyl)-1H-purin-6-amine (BA).
\end{abstract}

Grain legumes, including common bean (Phaseolus vulgaris L.), are somewhat recalcitrant to Agrobacterium tumefaciensmediated transformation and regeneration. Franklin et al. (1993) produced transformed GUS-positive callus from inoculation of a kidney bean cultivar with Agrobacterium tumefaciens strain EHA101. Putative transformants have been reported in one common bean cultivar (Mariotti et al., 1989); however, no molecular evidence of transformation or data on transmission through the seed was presented. Axillary bud tissue culture systems for wholeplant regeneration in bean have been developed (Franklin et al., 1991; McClean and Grafton, 1989). However, they have yet to be adapted successfully for use in an Agrobacterium-based transformation system (McClean et al., 1991). The transformation method of infecting the meristem of germinating seeds with Agrobacterium was used successfully in soybean (Chee et al., 1989). This procedure has the advantage of not requiring regeneration from tissue culture.

Genotypic differences in susceptibility of grain legumes to $A$. tumefaciens have been reported for pea (Hobbs et al., 1989; Puonti-Kaerlas et al., 1989, 1990) and soybean (Byrne et al., 1987; Delzer et al., 1990; Owens and Cress, 1985), but the basis for these differences is not well understood. Most susceptibility studies have involved scoring for tumorigenesis subsequent to inoculation. The possible association of phytohormone sensitivity and Agrobacterium-induced tumorigenesis has been suggested to ex-

Received for publication 16 Mar. 1993. Accepted for publication 19 July 1993. Part of a dissertation submitted by M.E. Lewis in partial fulfillment of the requirements for a $\mathrm{PhD}$ at the Univ. of Wisconsin, Madison. Mention of a trademark, proprietary product, or vendor does not constitute a guarantee or warranty of the product by the authors and does not imply its approval to the exclusion of other products or vendors that may also be suitable. The cost of publishing this paper was defrayed in part by the payment of page charges. Under postal regulations, this paper therefore must be hereby marked advertisement solely to indicate this fact.

${ }^{1}$ Research associate. Current address: Dept. of Horticulture, Michigan State Univ., East Lansing, MI 48824-1325.

${ }^{2}$ Professor and chair. plain differences in susceptibility (Van Wordragen et al., 1992). The use of the naturally occurring compound acetosyringone in a pre-inoculation culture step has been shown to increase the level of virulence in Agrobacterium (Vernade et al., 1988) and lead to higher transformation rates (Sheikholeslam and Weeks, 1987).

McClean et al. (1991) were able to induce a relatively high tumor frequency on seedling hypocotyls of 19 bean lines using $A$. tumefaciens strains A208, A281, and LBA 4001. However, those results were difficult to assess quantitatively because infection rates were reported only as the number of plants with at least one tumor. Using a GUS marker gene, particularly a construct such as that in pKIWI105 (Janssen and Gardner, 1989), that does not express GUS in Agrobacterium and therefore cannot lead to false background readings would provide a more direct means of assessing transformation rates. The objectives of this research were to examine aspects of susceptibility of common bean to oncogenic (tumor-forming) and disarmed-engineered (GUS-containing) strains of A. tumefaciens using the stab-inoculation technique.

\section{Materials and Methods}

Plant materials. Ten bean lines reflecting a portion of the variation present in common bean for market class (seed type), growth habit, frequency of Rhizobium nodulation, and the presence or absence of phaseolin (the major seed storage protein) were studied. These included line UW 325 (wild P. vulgaris var. mexicanus), 'Puebla 152' (prostrate, highly nodulating), 'Rio Tibagi' (poor nodulator), 'Tendergreen' and 'Montcalm' (both upright determinate), 'C-20' (upright indeterminate), 'Olathe' (prostrate), and lines BMC 3352, 11-33, and 13-41 (all phaseolin deficient).

Agrobacteria strains and inoculum preparation. The oncogenic strain C58-st, obtained from J. Slightom (Upjohn Molecular Biology Division, Kalamazoo, Mich.), was used in tumor-formation 
studies. The disarmed-engineered strain C58C1(pGV3850/ pKIWI105) (obtained from A. Dandekar, Univ. of CaliforniaDavis) contains the $n p t \mathrm{II}$ and uidA (GUS) marker genes. The GUS gene of pKIWI105 (Janssen and Gardner, 1989) cannot be expressed within the bacterium due to an alteration of the ribosome binding site. The disarmed strain C58C1(pGV3850) (also obtained from A. Dandekar) has no T-DNA region; it was used in some cases as a negative control.

A loop of freshly plated bacteria was used to initiate liquid cultures. Luria-Bertani medium (Sambrook et al., 1989) was used in solid- and liquid-phase culture systems for growing inoculum for the tumorigenesis assay; YEP medium ( $\mathrm{pH} 7$ ) (per liter: $10 \mathrm{~g}$ peptone, $10 \mathrm{~g}$ yeast extract, $5 \mathrm{~g} \mathrm{NaCl}$ ) was later found to promote faster growth (data not shown) and was used in all subsequent experiments. Liquid orbital shake cultures (200 rpm, $28 \pm 1.0 \mathrm{C}$ ) were grown overnight with the appropriate antibiotics and resuspended in Murashige and Skoog (MS) medium (Murashige and Skoog, 1962) with $2 \%$ sucrose (MS20) at pH 5.8 to an optical density of 1.3 at $600 \mathrm{~nm}$ (usually a 50\% dilution of the bacteria). In experiments subsequent to the tumorigenesis trial, a resuspension medium pH of 5.2 was used. In one transformation experiment, an overnight culture of strain C58C1(pGV3850/pKIWI105) was resuspended in MS20 medium ( $\mathrm{pH}$ 5.2) with $100 \mu \mathrm{M}$ acetosyringone and $1 \mathrm{~mm}$ betaine phosphate (Vernade et al., 1988). The concentration of the bacterial resuspension was set at an optical density of 1.3 at $600 \mathrm{~nm}$ and returned to rotary shake culture for $6 \mathrm{~h}$. Strain C58C1(pGV3850), used as a control, also was prepared in the same manner.

Tumorigenesis assay. Seedling shoot tips were stab-inoculated similarly to the method of Chee et al. (1989). Seeds of the 10 lines were mildly surface-sterilized (agitated at $150 \mathrm{rpm}$ for $10 \mathrm{~min}$ in $20 \%$ chlorine bleach) and rinsed four times with sterile deionized water. Seeds with testae that remained smooth were chipped to promote uniform imbibition, and all seeds were germinated at $25 \mathrm{C}$ in petri plates on Whatmann no. 3 filter paper moistened with a half-strength MS salt solution. After 1 or 2 days, when the seeds had swollen and the radical had begun to emerge, the seed coat and one cotyledon were removed. Under stereomicroscope magnification, the bases of the unifoliate leaves were partially removed to expose the shoot apical meristem. A 30-gauge needle attached to a $1-\mathrm{cm}^{3}$ syringe containing liquid Agrobacterium culture was used to wound the meristem region and deliver the inoculum. The inoculated "half-seedlings" were returned to the petri plates and incubated for 2 more days at $25 \mathrm{C}$ in darkness. Controls were inoculated with sterile half-strength MS20 medium.

Subsequently, the seedlings were transferred to pots containing a standard soil mix and grown in environment chambers with a 16$\mathrm{h}$ photoperiod of $\approx 500 \mu \mathrm{mol} \cdot \mathrm{m}^{-2} \cdot \mathrm{s}^{-1}, 25 / 17 \mathrm{C}$ (day/night), and $50 \% /$ $70 \%$ (day/night) relative humidity. Plants were scored for tumor frequency and tumor size 3 weeks after inoculation. Tumors were assigned a size score of 1 (<1 mm), 2 (1 to $4 \mathrm{~mm})$, or $3(>4 \mathrm{~mm})$. Frequency was calculated by recording the number of distinct sites with tumors on each plant and dividing by seven, the maximum number of tumor sites found among the inoculated plants (tumors often occurred on plant parts not directly inoculated). For example, a plant having a tumor at the unifoliate node and on a unifoliate leaf (either one or both leaves) would receive a score of $2 / 7$, or $29 \%$. Absolute tumor number could not be determined accurately because of the frequent inability to distinguish individual tumors.

In vitro culture of excised shoot tips. Germinating seedlings were stabbed in a manner similar to that described previously to test for phytohormone sensitivity, except that only sterile resuspension medium (no Agrobacterium) was used as an inocu- lum. After mock inoculation and 2 days of incubation at $25 \mathrm{C}$ in the dark, shoot apexes were excised directly above the cotyledonary node and cultured singly in 30-ml polystyrene blood sample vials (Fisher Scientific, Pittsburgh) on a medium containing MS salts, B5 vitamins (Gamborg et al., 1968), 3\% sucrose, cefotaxime (Claforan) at $500 \mathrm{mg} \cdot$ liter $^{-1}$, and $0.7 \%$ Phytagar (TC grade; Gibco, Grand Island, N.Y.) at pH 5.8 with 1) $11.1 \mu \mathrm{M} \mathrm{BA,} \mathrm{2)} 4.4 \mu \mathrm{M}$ BA and 10.7 $\mu \mathrm{M}$ NAA, or 3) $22.2 \mu \mathrm{M}$ BA and $2.7 \mu \mathrm{M}$ NAA. These growth regulator concentrations approximated those used by Kartha et al. (1984) (nos. 1 and 2) and Allavena and Rossetti (1986) (no. 3 ), which were found to promote callus formation, multiple budding, or both in bean shoot apex explants. These cultures were maintained at $24 \mathrm{C}$ under a $16-\mathrm{h}$ photoperiod of $100 \mu \mathrm{mol} \cdot \mathrm{m}^{-2} \cdot \mathrm{s}^{-1}$ provided by cool-white fluorescent bulbs. Explants were transferred to fresh medium after 2 and 9 days and evaluated for root and callus formation after 3 weeks.

Stab-inoculation with C58C1(pGV3850/pKIWI105). Germinating half-seeds were inoculated as previously described with the GUS-containing strain C58C1(pGV3850/pKIWI105). Control half-seedlings were inoculated with strain C58C1(pGV3850). After 1 day of incubation in petri plates on moistened filter paper in the dark, the inoculated half-seedlings were placed on cotton squares saturated with a MS salts solution in GA-7 vessels (Magenta Corp., Chicago) and exposed to a 16-h photoperiod at $24 \mathrm{C}$ as previously described. After 6 days, shoot apexes were excised just below the unifoliate node, and the unifoliate leaves, along with most of the petiole, were removed. This unifoliate node tissue was used for the fluorometric GUS analysis.

In a separate experiment, germinating seeds of line UW 325 were inoculated with strain C58C1(pGV3850/pKIWI105). The histochemical GUS assay was used to examine whole shoot tips for locating transformation events in the meristem. GUS-transformed walnut somatic embryos (obtained from G. McGranahan, Univ. of California-Davis) were used as positive controls in each fluorometric and histochemical GUS assay.

Biochemical assays for transformation. Tumor tissue from different plant sites of each line from the susceptibility evaluation experiment was assayed for the production of nopaline using paper chromatography as described by Otten and Schilperoort (1978). Fluorometric assays for GUS activity in unifoliate node tissue were conducted with the substrate 4-methylumbelliferyl $\beta$ D-glucuronide (MUG) (Sigma Chemical Co., St. Louis) as described by Jefferson (1987). The reaction mixture was incubated at 37C for $100 \mathrm{~min}$ plus an additional $10 \mathrm{~min}$ to allow for equilibration. To account for background fluorescence, part of the reaction mixture of six randomly chosen samples for each line was transferred to the stop buffer immediately after the reaction buffer was added. Histochemical GUS assays of UW 325 shoot tips were done using the substrate 5-bromo-4-chloro-3-indolylglucuronide (X-GLUC; Jersey Lab Supply, Livingston, N.J.). The excised shoot apex was sliced in half longitudinally and incubated in $1 \mathrm{~mm}$ X-GLUC for $6 \mathrm{~h}$ at 37C (Jefferson, 1987). Localized regions of transformed cells, as indicated by a blue precipitate, were detected visually under stereomicroscope magnification.

Statistical methods. Data were analyzed by using MSTAT 1.4-C (Michigan State Univ.). The C58 10-line evaluation was done twice; a randomized complete-block analysis of variance was performed on the combined data set, with each trial designated as a block. The F test for tumor size was done by hand (Snedecor, 1946) because of the unequal size of data sets among lines; a size score was assigned only if a tumor existed. Absolute GUS activity readings of the control (providing a measure of intrinsic GUS activity) and of GUS-inoculated materials were first subjected to 
within-line paired $t$ tests to determine if a significant amount of GUS activity was present over the controls. Comparisons among lines were made possible by subtracting the mean control GUS activity measurement from the individual GUS-inoculated readings of that particular line, thus producing a corrected GUS activity. These data were transformed by the function $\log (X+1)$ to correct for a mean-variance relationship (Gomez and Gomez, 1984) before analysis of variance as a completely randomized design.

\section{Results}

Tumorigenesis study. The susceptibility study uncovered significant differences among the 10 bean lines for tumor frequency and size (Table 1 and Fig. 1). Tumors occurred at up to seven different plant sites: the hypocotyl, cotyledonary node, epicotyl internode, unifoliate node, unifoliate petiole, unifoliate leaf, and the first trifoliolate node. Although most plants (87\% to $100 \%)$ had at least one tumor, tumorigenesis scores ranged from a high of $58.7 \%$ for UW 325 to a low of $24.4 \%$ for 'Olathe'. The line $\times$ replicate interaction was not significant. The range of differences for tumor size was smaller; UW 325 and 'Montcalm' had the largest tumors, while 13-41 and 'Puebla 152' had the smallest. Control stabbed seedlings (two per line) formed no tumors.

The lines that had the highest overall frequency of tumor formation also had high rates of tumorigenesis at the unifoliate node (Table 2). In the case of 'Tendergreen', a high rate of tumor formation also occurred at the trifoliolate node. Due to occasional disruption of the meristem by tumor growth, trifoliolate nodes were sometimes absent (especially on UW 325). These plants were not included in the tabulation of the data for trifoliolate node tumor frequency. The unifoliate leaf site had the highest mean frequency of tumors $(86 \%)$ over all lines. Tumors rarely formed on the hypocotyl and epicotyl (7\% and $9 \%$, respectively). Tissue samples of tumors from different positions on the plant from a random sample of plants of each line tested positive for the production of nopaline without exception. Control shoot tips and in vitro-induced 'Tendergreen' callus tested negative for nopaline (data not shown). The three most tumorigenic lines (UW 325, 'Tendergreen', and 'Montcalm') and the two lines that formed tumors least frequently ('Puebla 152', which also had the second lowest tumor size score, and 'Olathe') were used in further studies.

Table 1. Tumor formation on 10 common bean lines 3 weeks after stab-inoculation with Agrobacterium tumefaciens strain C58.

\begin{tabular}{|c|c|c|c|c|}
\hline $\begin{array}{l}\text { Bean } \\
\text { line }\end{array}$ & $\begin{array}{l}\text { Total } \\
\text { no. of } \\
\text { plants }\end{array}$ & $\begin{array}{l}\text { Plants with } \\
\text { at least one } \\
\text { tumor }(\%)\end{array}$ & $\begin{array}{c}\text { Tumor } \\
\text { frequency } \\
\text { (\% of seven } \\
\text { sites) }\end{array}$ & $\begin{array}{c}\text { Tumor } \\
\text { size } \\
\text { score }^{\mathrm{z}}\end{array}$ \\
\hline UW 325 & 22 & 100.0 & $58.7 \mathrm{a}^{\mathrm{y}}$ & $2.1 \mathrm{a}$ \\
\hline Tendergreen & 24 & 100.0 & $52.4 \mathrm{a}$ & $2.0 \mathrm{a}$ \\
\hline Montcalm & 22 & 100.0 & $42.6 \mathrm{~b}$ & $2.1 \mathrm{a}$ \\
\hline $11-33$ & 23 & 100.0 & $40.6 \mathrm{bc}$ & $2.0 \mathrm{a}$ \\
\hline C-20 & 22 & 100.0 & $34.3 \mathrm{~cd}$ & $1.7 \mathrm{~b}$ \\
\hline Rio Tibagi & 24 & 91.7 & $28.9 \mathrm{de}$ & $1.9 \mathrm{ab}$ \\
\hline $13-41$ & 24 & 100.0 & $28.0 \mathrm{de}$ & $1.3 \mathrm{c}$ \\
\hline BMC 3352 & 23 & 87.0 & $27.8 \mathrm{de}$ & $1.7 \mathrm{~b}$ \\
\hline Puebla 152 & 24 & 91.7 & $26.2 \mathrm{de}$ & $1.4 \mathrm{c}$ \\
\hline Olathe & 24 & 95.8 & $24.4 \mathrm{e}$ & $1.7 \mathrm{~b}$ \\
\hline Mean & & 96.6 & 36.4 & 1.8 \\
\hline
\end{tabular}

ZTumor size: 1 is $<1 \mathrm{~mm}, 2$ is 1 to $4 \mathrm{~mm}, 3$ is $>4 \mathrm{~mm}$ in diameter. yean separation by Duncan's multiple range test, $P \leq 0.05$.
Hormone sensitivity of excised shoot tips. Shoot tips of the five lines cultured in media with BA or BA plus NAA displayed significant differences for callus and root formation (Table 3 ). The means of the three growth regulator combinations were pooled because there were no significant changes in rank among media treatments. 'Montcalm' and 'Tendergreen' shoot tips consistently had the largest basal calli (overall means of 13.6 and $12.6 \mathrm{~mm}$, respectively). 'Olathe' seemed to be fairly recalcitrant to callusing (mean basal callus diameter of only $4.6 \mathrm{~mm}$ ). Phytohormone sensitivity was also reflected in the propensity to form roots in response to auxin (NAA) in the medium. The rate of root formation paralleled the tendency to callus with one exception: UW 325 had the highest frequency of explants with roots and only an intermediate callus size. The lines that seemed to have the highest phytohormone sensitivity, 'Montcalm' and 'Tendergreen', were also among the most highly tumorigenic (Table 1). 'Olathe' had low tumorigenesis scores (Table 1) and also was insensitive to phytohormone-induced callusing.

GUS analysis of inoculated seedlings. Of the five lines inoculated with the GUS-containing strain C58C1(pGV3850/ pKIWI105), only 'Olathe', a line with a low frequency of tumor formation, had no significant level of fluorometric GUS activity over the control (Table 4). The higher levels of endogenous GUS activity in the 'Tendergreen' and 'Olathe' controls may have been due to the presence of a GUS-like enzyme or to microbial endophytes with GUS activity. After accounting for intrinsic GUS

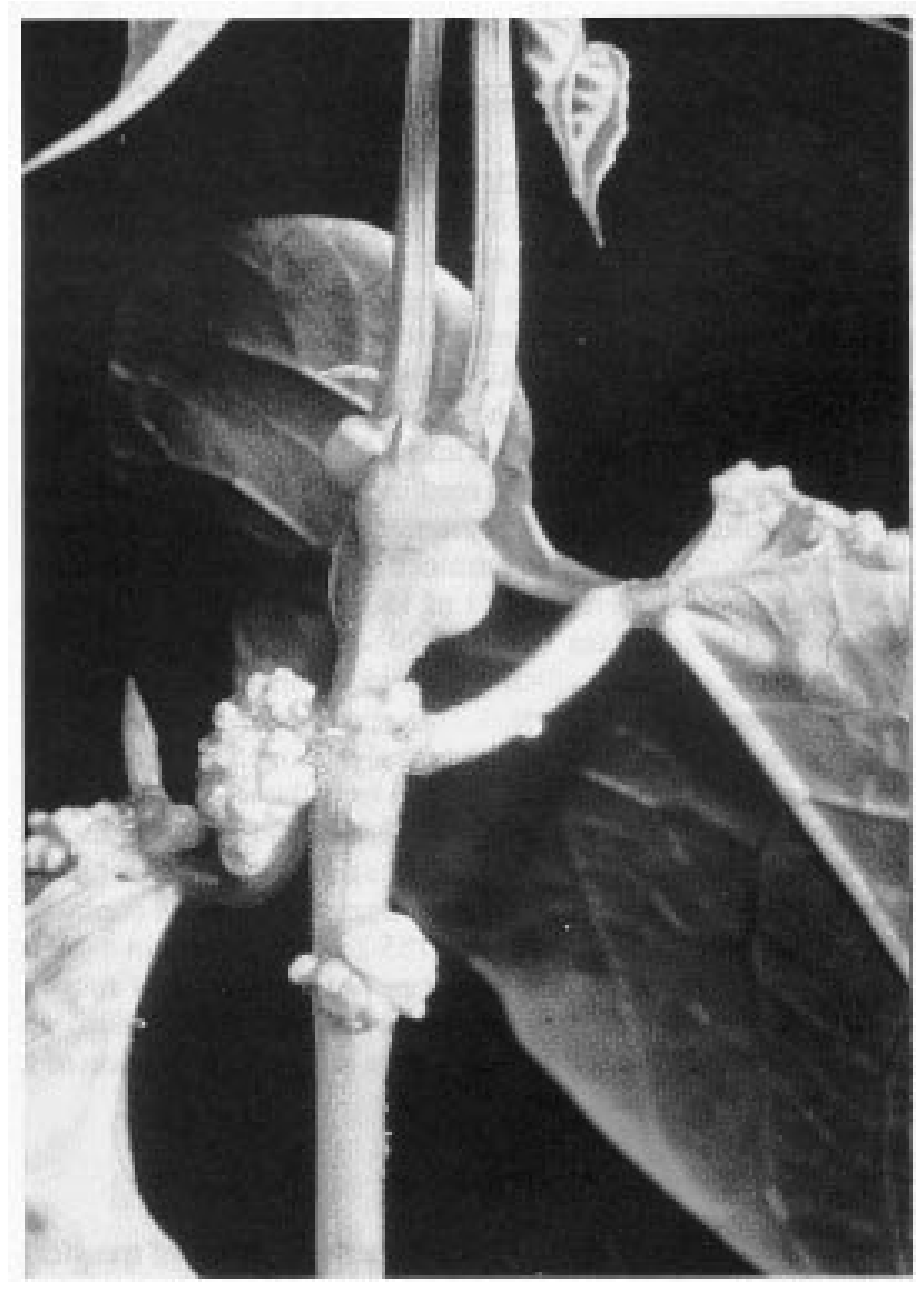

Fig. 1. Tumors on the unifoliate node region of 'Tendergreen' 3 weeks after stab-inoculating the germinating seed with Agrobacterium tumefaciens strain C58. 
Table 2. Frequency of tumors at seven sites on plants of five common bean lines 3 weeks after stab-inoculation with Agrobacterium tumefaciens strain C58.

\begin{tabular}{|c|c|c|c|c|c|c|c|c|}
\hline \multirow{2}{*}{$\begin{array}{l}\text { Bean } \\
\text { line }\end{array}$} & \multirow{2}{*}{$\begin{array}{l}\text { No. of } \\
\text { plants }\end{array}$} & \multicolumn{7}{|c|}{ Tumor sites ${ }^{z}$} \\
\hline & & hy & $\mathrm{cn}$ & ep & un & up & ul & tn \\
\hline \multicolumn{9}{|c|}{ Percentage of plants with tumors } \\
\hline UW 325 & 22 & 32 & 82 & 0 & 100 & 82 & 64 & $22^{y}$ \\
\hline Tendergreen & 24 & 8 & 62 & 25 & 71 & 38 & 100 & 67 \\
\hline Montcalm & 22 & 0 & 14 & 18 & 91 & 59 & 91 & 25 \\
\hline Puebla 152 & 24 & 4 & 12 & 4 & 46 & 12 & 83 & 21 \\
\hline Olathe & 24 & 4 & 21 & 0 & 54 & 12 & 71 & 4 \\
\hline All lines & & 7 & 28 & 9 & 65 & 36 & 86 & 19 \\
\hline
\end{tabular}

${ }^{\mathrm{z}}$ Abbreviations: hy $=$ hypocotyl, $\mathrm{cn}=$ cotyledonary node, $\mathrm{ep}=$ epicotyl, $\mathrm{un}=$ unifoliate node, $\mathrm{up}=$ unifoliate petiole, $\mathrm{ul}=\mathrm{unifoliate}$ leaf (the pair was regarded as only one site), $\mathrm{tn}=$ first trifoliolate node.

${ }^{\mathrm{y}}$ Due to frequent disruption of UW 325 meristems by a unifoliate node tumor, trifoliolate nodes were often absent. The figure of $22 \%$ represents only two of the nine plants having trifoliolate nodes.

Table 3. Basal callus diameter and frequency of root formation on excised cultured shoot tips of five common bean lines 3 weeks after mock stab-inoculation.

\begin{tabular}{lccc}
\hline \hline $\begin{array}{l}\text { Bean } \\
\text { line }\end{array}$ & $\begin{array}{c}\text { No. of } \\
\text { explants }\end{array}$ & $\begin{array}{c}\text { Callus } \\
\text { diam } \\
(\mathrm{mm})\end{array}$ & $\begin{array}{c}\text { Proportion of } \\
\text { tips forming } \\
\text { roots }(\%)\end{array}$ \\
\hline Montcalm & 27 & $13.6 \mathrm{a}^{\mathrm{z}}$ & 52 \\
Tendergreen & 27 & $12.6 \mathrm{a}$ & 56 \\
UW 325 & 27 & $7.2 \mathrm{~b}$ & 63 \\
Puebla 152 & 27 & $7.6 \mathrm{~b}$ & 30 \\
Olathe & 26 & $4.6 \mathrm{c}$ & 23 \\
\hline
\end{tabular}

${ }^{\mathrm{z}}$ Mean separation by Duncan's multiple range test, $P \leq 0.05$.

activity, it was apparent that line UW 325 (169.6 pM/mg per min 4-MU) and 'Tendergreen' (93.6 pM/mg per min 4-MU) had the highest levels of GUS activity. The level of GUS activity in 'Montcalm', one of the more highly tumorigenic lines (Table 1), was moderately low and was no higher than in 'Puebla 152', a weakly tumorigenic line. Pretreating bacteria with acetosyringone led to a general decrease in GUS activity (data not shown) except in UW 325, which seemed to have a dramatically increased level of expression (434.5 $\mathrm{pM} / \mathrm{mg}$ per min 4-MU).

The shoot apexes of UW 325 seedlings stab-inoculated with the GUS-containing strain had one or more regions of GUS expression in the area of the meristem (determined by histochemical analysis) in 13 of 25 (after 6 days) and 11 of 15 (after 15 days) shoot tips examined. These apexes (total of 24 ) had an average of $\approx 2.5$ GUS-positive regions, which appeared as blue zones. Stabbed seedlings were assayed at 6 days, corresponding to the time period used previously for the fluorometric analysis, or 15 days, by which time many shoot apexes had recovered from the wounding caused by stabbing and resumed growth. In addition, a fluorometric analysis done on 6-day-old shoot apexes of 12 seedlings stab-inoculated with the GUS-containing strain (plus 8 controls) had a mean level of GUS activity (185.2 pM/mg per min 4-MU) similar to the reading obtained in an earlier experiment (Table 4). Although transformation occurred in the meristem region, no continuing cell lineages that might have led to the formation of a transformed shoot were seen.

\section{Discussion}

Stab-inoculating seedlings is an attractive method of transformation because it does not require tissue culture regeneration. Further, it creates a wound site, which is necessary for infection
(Kado, 1991), and exposes the interior cell layers of the meristem to Agrobacteria. Transformation of these layers would allow a subsequently arising germline cell to pass on the acquired transgene through the seed. The procedure is rapid, taking only 3 weeks from inoculation to date of scoring.

The tumor frequency score indicated susceptibility to A. tumefaciens strain C58. Nodal tumor frequency relates more directly to the probability of producing a transformed shoot from inoculations with a disarmed-engineered strain. There did not seem to be an association of Agrobacterium susceptibility with any particular bean line attribute, such as region of ancestral origin, growth habit, or nodulation capability. For example, UW 325 (Mesoamerican origin, indeterminate climbing growth habit) and 'Tendergreen' (Andean origin, upright determinate growth habit) were highly susceptible. The rate of tumor formation for 'Puebla 152' (highly susceptible to nodulation by Rhizobium; Bliss, 1987) was similar to that of 'Rio Tibagi' (less susceptible to Rhizobium nodulation; F.A. Bliss, unpublished results).

There were significant differences in response (sensitivity) of mock-inoculated cultured shoot tips to growth regulators. It was anticipated that perhaps the highly tumorigenic nature of 'Tendergreen' and 'Montcalm' was the result of a high phytohormone sensitivity, as shown by the tendency to form large amounts of callus in vitro. Agrobacterium-induced tumors result from cell proliferation induced by the products of the T-DNA phytohormone oncogenes. Still, it was possible that these lines were highly susceptible to Agrobacterium and highly sensitive to phytohormones. 'Olathe' had the lowest phytohormone sensitivity and the lowest overall tumorigenesis score. But it was conceivable that the paucity of tumor formation on this line was due simply to an insensitivity to the phytohormones produced, and that it might actually be reasonably susceptible to Agrobacterium. The wild line UW 325 did not follow the same pattern of response as the other four lines. While being highly tumorigenic, it had only a moderate level of in vitro callus formation.

Tumorigenesis assays are simple to perform. However, tumor formation, as a measure of susceptibility, depends on expression of the oncogenic transgenes and on the phytohormone sensitivity of the plant. In contrast, the GUS marker gene allows for direct determination of the transformation rate as a measure of susceptibility. The GUS enzyme that is encoded by the uidA gene does not depend on plant substrates for expression. Further, the GUS gene found in pKIWI105 is not expressed within the Agrobacterium itself. This provides an opportunity for early transformation events to be assayed without concern for residual Agrobacterium GUS activity. 
Table 4. Fluorometric GUS activity of excised shoot tips from seedlings of five common bean lines 6 days after stab-inoculation with Agrobacterium tumefaciens strain C58C1(pGV3850/pKIWI105).

\begin{tabular}{|c|c|c|c|c|}
\hline \multirow{2}{*}{$\begin{array}{l}\text { Bean } \\
\text { line }\end{array}$} & \multirow[b]{2}{*}{ Treatment } & \multirow{2}{*}{$\begin{array}{c}\text { No. of } \\
\text { shoot } \\
\text { tips }\end{array}$} & \multicolumn{2}{|c|}{$\begin{array}{c}\text { GUS activity } \\
\text { (pM/mg per min 4-MU) }\end{array}$} \\
\hline & & & Absolute & Corrected \\
\hline \multirow[t]{2}{*}{$\overline{U W} 325$} & Control & 6 & 11.8 & \\
\hline & pKIWI105 & 36 & $181.4^{* *}$ & $169.9 \mathrm{a}^{\mathrm{z}}$ \\
\hline \multirow[t]{2}{*}{ Tendergreen } & Control & 6 & 31.7 & \\
\hline & pKIWI105 & 36 & $124.7^{* *}$ & $93.6 \mathrm{~b}$ \\
\hline \multirow[t]{2}{*}{ Montcalm } & Control & 5 & 13.8 & \\
\hline & pKIWI105 & 32 & $36.8^{* *}$ & $23.7 \mathrm{c}$ \\
\hline \multirow[t]{2}{*}{ Puebla 152} & Control & 5 & 14.9 & \\
\hline & pKIWI105 & 36 & $36.6^{* *}$ & $21.8 \mathrm{c}$ \\
\hline \multirow[t]{2}{*}{ Olathe } & Control & 6 & 35.6 & \\
\hline & pKIWI105 & 35 & $39.8^{\mathrm{NS}}$ & NS \\
\hline
\end{tabular}

${ }^{\mathrm{z}}$ Mean separation by Duncan's multiple range test, $P \leq 0.01$. Statistical analysis was performed with $\log (\mathrm{X}+1)$ transformed data; original data are shown.

Ns,**N Nonsignificant or significant at $P \leq 0.01$ as determined by paired $t$ tests.

The C58 tumorigenesis tests were useful for measuring susceptibility with one exception. 'Montcalm', a highly tumorigenic line, turned out to be no more susceptible than 'Puebla 152', a weakly tumorigenic line, as measured by the GUS activity of pKIWI105-inoculated shoot tips. It seems that 'Montcalm' was merely more phytohormone-sensitive than 'Puebla 152'. UW 325 had a high tumorigenesis score despite being only moderately phytohormone-sensitive because of high susceptibility to Agrobacterium, as shown by a high level of GUS expression. The pre-induction of virulence did not raise the level of transformation in four of the five lines. This provided evidence that differences in susceptibility among the lines were not due to differences in the amounts or types of virulence-inducing compounds produced by the plant.

A histochemical assay of putatively GUS-transformed UW 325 shoot apexes detected expression of GUS at a fairly high frequency. The results of the fluorometric assay of the five lines inoculated with the GUS-containing strain did not reveal where in the shoot tip transformation was occurring. Since UW 325 has a high frequency of tumors on the petiole (82\%), it was conceivable that a significant amount of the GUS fluorometric activity was a result of transformation in the remaining petiole stub, rather than in the meristem. However, most of the shoot tips in the histochemical assay had one or more transformation events in the meristem.

Because of the position of the blue-staining zones in the shoot apex, it was apparent that none of the transformation events was in continuing cell lineages of the meristem. Perhaps if more seeds were inoculated, cells in the meristem leading to a transformed shoot may be infected by Agrobacterium. On the other hand, it is possible that a meristem exclusion mechanism, such as that occurring in the case of many viral infections, may be functioning in Agrobacterium infection of the meristem (Potrykus, 1991).

\section{Literature Cited}

Allavena, A. and L. Rossetti. 1986. Micropropagation of bean (Phaseolus vulgaris L.); effect of genetic, epigenetic, and environmental factors. Scientia Hort. 30:37-46.

Bliss, F.A. 1987. Host plant control of symbiotic $\mathrm{N}_{2}$ fixation in grain legumes, p. 479-493. In: W.H. Gabelman and B.C. Loughman (eds.). Genetic aspects of plant mineral nutrition. Martinus Nijhoff Publ., Boston.

Byrne, M.C., R.E. McDonnell, M.S. Wright, and M.G. Carnes. 1987. Strain and cultivar specificity in the Agrobacterium-soybean interac- tion. Plant Cell Tissue Organ Cult. 8:3-15.

Chee, P.P., K.A. Fober, and J.L. Slightom. 1989. Transformation of soybean (Glycine max) by infecting germinating seeds with Agrobacterium tumefaciens. Plant Physiol. 91:1212-1218.

Delzer, B.W., D.A. Somers, and J.H. Orf. 1990. Agrobacterium tumefaciens susceptibility and plant regeneration of 10 soybean genotypes in maturity groups 00 to II. Crop Sci. 30:320-322.

Franklin, C.I., T.N. Trieu, B.G. Cassidy, R.A. Dixon, and R.S. Nelson. 1993. Genetic transformation of green bean callus via Agrobacterium mediated DNA transfer. Plant Cell Rpt. 12:74-79.

Franklin, C.I., T.N. Trieu, R.A. Gonzales, and R.A. Dixon. 1991. Plant regeneration from seedling explants of green bean (Phaseolus vulgaris L.) via organogenesis. Plant Cell Tissue Organ Cult. 24:199-206.

Gamborg, O.L., R.A. Miller, and K. Ojima. 1968. Nutrient requirements for suspension cultures of soybean root cells. Expt. Cell Res. 50:151158.

Gomez, K.A. and A.A. Gomez. 1984. Statistical procedures for agricultural research. Wiley, New York.

Hobbs, S.L.A., J.A. Jackson, and J.D. Mahon. 1989. Specificity of strain and genotype in the susceptibility of pea to Agrobacterium tumefaciens. Plant Cell Rpt. 8:274-277.

Janssen, B.-J. and R.C. Gardner. 1989. Localized transient expression of GUS in leaf discs following cocultivation with Agrobacterium. Plant Mol. Biol. 14:61-72.

Jefferson, R.A. 1987. Assaying chimeric genes in plants: The GUS gene fusion system. Plant Mol. Biol. Rpt. 5:387-405.

Kado, C.I. 1991. Molecular mechanisms of crown gall tumorigenesis. Critical Rev. Plant Sci. 10:1-32.

Kartha, K.K., K. Pahl, N.L. Leung, and L.A. Mroginski. 1981. Plant regeneration from meristems of grain legumes: Soybean, cowpea, peanut, chickpea, and bean. Can. J. Bot. 59:1671-1679.

Mariotti, D., G.S. Fontana, and L. Santini. 1989. Genetic transformation of grain legumes: Phaseolus vulgaris L. and P. coccineus L. J. Genet. Breeding 43:77-82.

McClean, P., P. Chee, B. Held, J. Simental, R.F. Drong, and J. Slightom. 1991. Susceptibility of dry bean (Phaseolus vulgaris L.) to Agrobacterium infection: Transformation of cotyledonary and hypocotyl tissues. Plant Cell Tissue Organ Cult. 24:131-138.

McClean, P. and K.F. Grafton. 1989. Regeneration of dry bean (Phaseolus vulgaris L.) via organogenesis. Plant Sci. 60:117-122.

Murashige, T. and F. Skoog. 1962. A revised medium for rapid growth and bioassays with tobacco tissue cultures. Physiol. Plant. 15:473-497.

Owens, L.D. and D.E. Cress. 1985. Genotypic variability of soybean response to Agrobacterium strains harboring the Ti or Ri plasmids. Plant Physiol. 77:87-94.

Otten, L. and R.A. Schilperoort. 1978. A rapid micro scale method for the detection of lysopine and nopaline dehydrogenase activities. Biochim. 
Biophys. Acta 527:497-500.

Potrykus, I. 1991. Gene transfer to plants: Assessment of published approaches and results. Annu. Rev. Plant Physiol. Plant Mol. Biol. 42:205-225.

Puonti-Kaerlas, J., T. Eriksson, and P. Engstrom. 1990. Production of transgenic pea (Pisum sativum L.) plants by Agrobacterium tumefaciens- mediated gene transfer. Theoretical Applied Genet. 80:246-252.

Puonti-Kaerlas, J., P. Stabel, and T. Eriksson. 1989. Transformation of pea (Pisum sativum L.) by Agrobacterium tumefaciens. Plant Cell Rpt. 8:231-234

Sambrook, J., E.F. Fritsch, and T. Maniatis. 1989. Molecular cloning. A laboratory manual. Cold Spring Harbor Laboratory Press, Cold Spring Harbor, N.Y.
Sheikholeslam, S.N. and D.P. Weeks. 1987. Acetosyringone promotes high efficiency transformation of Arabidopsis thaliana explants by Agrobacterium tumefaciens. Plant Mol. Biol. 8:291-298.

Snedecor, G.W. 1946. Statistical methods applied to experiments in agriculture and biology. Iowa State College Press, Ames.

Van Wordragen, M.F., J. De Jong, M.J. Schornagel, and H.J.M. Dons. 1992. Rapid screening for host-bacterium interactions in Agrobacterium-mediated gene transfer to chrysanthemum, by using the GUS-intron gene. Plant Sci. 81:207-214.

Vernade, D., A. Herrera-Estrella, K. Wang, and M. Van Montagu. 1988. Glycine betaine allows enhanced induction of the Agrobacterium tumefaciens vir genes by acetosyringone at low $\mathrm{pH}$. J. Bacteriol. 170:58225829. 